\title{
Editorial
}

Volume 10 Number 1, June 2011

\section{Disaster Medicine-Is it time we embrace it?}

World Health Organization (WHO) defines 'a disaster as serious disruption of the function of a society causing widespread human, material or environmental losses which exceed the ability of the affected society to cope using only its own resources'. ${ }^{1}$ We have been unfortunate to have lived through three of these calamitous events within the last seven years. In December of 2004 an earthquake with a magnitude of 9.1 of the coast of Sumatra unleashed a tsunami that devastated the coasts of Aceh in Indonesia, Sri Lanka, Thailand, India and ended up traveling as far as the east African coastline, resulting in more than 240,000 deaths and immense hardship to several millions. ${ }^{2}$ Most of the countries affected were developing countries having relatively basic infrastructure with regard to transport, communications and health facilities. These inadequacies affected the immediate management of the disaster resulting in further injuries and loss of life. These countries are still to recover fully from the impact. They were unprepared for disasters of this nature and thus the colossal loss of lives and destruction.

In August 2005 Hurricane Katrina, one of the strongest in recent times, caused severe mayhem in the United States of America. As the storm made ashore it caused widespread destruction along the central Gulf Coast states. One of the most developed countries in the world and a global super power at that time was struggling to cope. The whole world was witness to the lack of preparedness and subsequent mismanagement of the response to this catastrophe even though it has been called the most anticipated disaster in modern American history. In addition to loss of lives, the damage to property, the oil industry and the infrastructure was estimated to be over 100 billion dollars. ${ }^{3}$

We witnessed yet another tsunami in the most developed country in the world, Japan. Even with heightened awareness and anticipation of tsunami in this earthquake prone area a disaster could not be avoided. The 8.9-magnitude tremor with its epicenter near the east coast of Japan resulted in thousands of deaths, hundreds of thousands homeless or evacuated from the area and vast damage to property. ${ }^{4}$ This event unfolded a new form of man-made disaster that is still ongoing, the fallout from the serious damage to the Fukushima nuclear reactor. Said to be potentially worse than the Chernobyl nuclear disaster, this resulted in the massive evacuation of residents residing in the vicinity of these reactors. The ensuing material cost of the earthquake and subsequent tsunami could cost over $\$ 300$ billion and may be the world's most costly natural disaster to date.

\section{What have we learnt from these catastrophes?}

A medical personnel's responsibility is to provide care for illnesses and injury during a disaster. Unlike other areas in medicine, in a disaster situation doctors have to function as part of a non-medical based multidisciplinary team. To be an effective member of this team it is essential that we are adequately exposed to and be familiar with the non-medical components of a disaster management response. It engulfs both emergency medicine and disaster management. This is sometimes referred to as Disaster Medicine. Disaster management medicine started as a distinct entity in the mid eighties, but it is still an evolving field. Most western countries now have embarked on Disaster Medicine as a sub-specialty. The current method of medical response to disasters has its origin from experience gained during military conflicts.

Although Malaysia has very advanced infrastructure on par with any advanced nation in the world, the ability of the medical fraternity to face a challenge of a major natural disaster has not been adequately tested. If we are to respond appropriately and effectively to a major disaster, it is our duty to pursue the necessary avenues to acquire knowledge and training.

Usually our role as a member of the disaster team is thrust on us by circumstances rather than by choice. We may be asked to see or deal with problems that are not your field of practice and may involve other medical disciplines. It is imperative that all medical personnel should possess the basic knowledge in disaster medicine and disaster management.

Preparedness entails developing a formal program to respond to a disaster. A structured training and staff development programme should be the first priority. With it, stratifying public health resources including facilities, supplies and personnel should follow. Formulation of standard operating procedures and emergency response plans are vital for successful implementation of the disaster management. It is mandatory for health personnel in collaboration with other involved agencies to conduct and actively participate in drills and exercises to familiarize each and every agency and individual's role and ability. This will enable the response to a disaster to be better coordinated and more focused. As in the case in Fukushima the main thrust involves the public health personnel to implement preventive measures in controlling the effects of radiation leak.

Although there will be Disaster management teams at the National and State levels, it our duty to ensure the presence of a functioning disaster management 
plan or disaster medical unit at the District level too. It enables the respective individuals to know their roles and to react to a specific situation. These units can be based at District hospitals under the head of the Emergency Medicine Unit of the respective hospital. Regular interactions and meetings should be held with all other emergency services. Frequent drills and exercises including hospital disaster simulation exercises are mandatory.

Education and training in disaster medicine is an ongoing process to all categories of personnel involved. In addition to the collaborative inter-professional table top exercises, regularly conducted field exercise drills offers the best form of training. Currently in most countries there is no standardized curriculum for the training of disaster management from the medical perspective. It is imperative that the concept of disaster medicine and its principles should be a component in the undergraduate and postgraduate curriculum of Medical and Allied health related programmes. We should not wait for a disaster to strike before we act.

\author{
Professor Dr Nasser Muhammad Amjad \\ Deputy Dean \\ Research and Postgraduate Affairs \\ Kulliyyah of Medicine \\ International Islamic University Malaysia
}

\title{
REFERENCES
}

1. UNDHA (2001). United Nations Department of Humanitarian Affairs: Internationally agreed glossary of basic terms related to Disaster Management. United Nations International Strategy for Disaster Reduction. Available at http://www.unisdr.org/unisdr/glossaire.htm [Geo-2-335]

2. Athukorala PC, Resosudarmo BP. The Indian Ocean Tsunami: Economic Impact, Disaster Management, and Lessons. Asian Economic Papers 2005; 4:1-39.

3. Cashell BW, Labonte M. The Macroeconom ic Effects of Hurricane Katrina. 2005 CRS Report for Congress. Available at http: / / assets.opencrs.com/ rpts/ RS22260_20050913.pdf.

4. Tsunami Facts in Wake of Japan Earthquake. National Geographic News Published March 11, 2011. Available at http://news.nation algeographic.com/news/2011/03/110311tsunami-facts-japan-earthquake. 